\title{
Cytoreductive surgery and hyperthermic intraperitoneal chemotherapy (HIPEC) in colorectal cancer with peritoneal metastasis: Status quo and how should we proceed
}

\author{
Ingmar Königsrainer
}

(C) Springer-Verlag GmbH Austria, part of Springer Nature 2020

Metastatic disease in colorectal cancer (CRC) is a challenging multidisciplinary disease, nowadays, embracing all oncological disciplines.

In selected patients, radical surgery is an opportunity for curing patients or important to "chronify" disease. This was clearly shown for years in metastatic liver disease from CRC.

In peritoneal metastasis (PM) surgery has become a dominant key in selected patients reaching a median overall survival of over 40 months [1]. The role of hyperthermic intraperitoneal chemotherapy (HIPEC), alone, is still unclear, especially due to the lack of randomized controlled trials. Prodigy 7 proved the dominant role of surgery questioning HIPEC. The "one shot" and effectiveness of, mostly used oxaliplatin remains questionable in this setting [1].

Surgery in general has become more minimally invasive. Whenever possible laparoscopy should be performed to estimate the peritoneal carcinomatosis index (PCI) and assess critical regions such as the small bowel. Diagnostic laparotomies should be avoided whenever possible. Liver metastasis in patients with limited peritoneal spread is no longer a contraindication for surgery [2].

In this special issue of the Magazine of European Medical Oncology (MEMO) a multidisciplinary team of experts summarize and discuss recent developments and the importance of HIPEC. Cytoreductive surgery (CRS) and HIPEC should be performed with moderate PCI $(<15)$ and $\leq$ three resectable liver metastases and, if applied, response to systemic chemotherapy [3]. Gasser et al. confirmed in their review that

\section{Prim. Prof. Dr. I. Königsrainer $(\varangle)$}

Department of General, Visceral and Thoracic

Surgery, Landeskrankenhäuser Feldkirch/Bludenz,

Carinagasse 47, 6800 Feldkirch, Austria

ingmar.koenigsrainer@lkhf.at
$\mathrm{CRS} \pm$ HIPEC will play a significant role in the future [4]. New innovative trial designs as proposed in the article from Yurtas et al. [5] may be needed, based on the difficulty of creating a prospective study, including potent intravenous chemotherapy regimens.

The present uncertainty about HIPEC in CRC with $\mathrm{PM}$ in the community should not lead to abandonment of this multimodal treatment approach, but strengthen the important role of surgery in this disease and proceed to redefine the role of HIPEC.

Best regards,

\section{Ingmar Königsrainer}

Conflict of interest I. Königsrainer declares that he has no competing interests.

\section{References}

1. Quenet F, Elias D, Roca L, Goere D, Ghouti L, Pocard M, et al. A UNICANCER phase III trial of hyperthermic intraperitoneal chemotherapy (HIPEC) for colorectal peritoneal carcinomatosis (PC): PRODIGE 7. J Clin Oncol. 2018; https://doi.org/10.1200/JCO.2018.36.18_SUPPL.LBA3503.

2. Maggiori L, Goéré D, Viana B, Tzanis D, Dumont F, Honoré Ch, et al. Should patients with peritoneal carcinomatosis of colorectal origin with synchronous liver metastases be treated with a curative intent? A case-control study. Ann Surg. 2013;258(1):116-21.

3. Horvarth P, Königsrainer I. Patient selection for cytoreductive surgery and hyperthermic intraperitoneal chemotherapy in colorectal cancer. memo. 2020;13(4). https://doi. org/10.1007/s12254-020-00633-w.

4. Gasser E, Kogler P, Lorenz A, Kafka-Ritsch R, Öfner D, Perathoner A. Do we still need CRS and HIPEC in colorectal cancerintimes ofmodern chemotherapyandimmunotherapy? memo. 2020;13(4) https://doi.org/10.1007/s12254020-00647-4. 


\section{editorial}

5. Yurttas C, Fisher OM, Cortés-Guiral D, Haen SP, Königsrainer IA, Beckert S, Liauw W,-Löffer MW. Cytoreductive surgery and HIPEC in colorectal cancer-did we get hold of the wrong end of the stick? memo 2020;13(4).https://doi. org/10.1007/s12254-020-00653-6.

Publisher's Note Springer Nature remains neutral with regard to jurisdictional claims in published maps and institutional affiliations.

- For latest news from international oncology congresses see: http://www.springermedizin.at/ memo-inoncology 